\title{
O ESTADO DE ALERTA: UM ESTUDO EXPLORATÓRIO COM O CORPO DE BOMBEIROS
}

\author{
Alert state: \\ An exploratory study with the fire brigade \\ El estado de alerta: \\ Un estudio exploratorio con el cuerpo de bomberos
}

\author{
Rosa Maria Bracini Gonzales \\ Joanita Cechin Donaduzzi
}

\author{
Carmem Lúcia Colomé Beck \\ Lilian Medianeira Coelho Stekel
}

\begin{abstract}
Resumo
Este estudo, inspirado na tese de doutorado de Beck ${ }^{1}$, com os enfermeiros que atuam em unidades críticas, teve como objetivo identificar a presença e caracterizar o Estado de Alerta nos trabalhadores do Corpo de Bombeiros, bem como estabelecer relações entre doenças provenientes do trabalho e Estado de Alerta, além de identificar estratégias de intervenção sugeridas pelos trabalhadores para melhorar sua qualidade de vida. Estes desenvolvem atividades submetidos a eventos situacionais inesperados nos quais a carga física e psíquica pode predispor o Estado de Alerta. Caracteriza-se como uma pesquisa da área humano-social, exploratória, com abordagem qualitativa que envolveu 24 trabalhadores. Para a coleta de dados, realizou-se entrevista semi-estruturada, composta por questões gerais e específicas. Na análise dos dados, foram mapeados o Estado de Alerta e sua relação com doenças identificadas pelos trabalhadores, apontando a necessidade de mudanças que favoreçam a melhoria da qualidade de vida no trabalho.
\end{abstract}

Palavras-chave: Nível de alerta. Enfermagem. Satisfação no trabalho. Qualidade de vida.

\section{Resumen}

Este estudio, inspirado en la tesis de doctorado de Beck ${ }^{1}$ con los enfermeros que actúan en unidades críticas, tuvo como objetivo identificar la presencia y caracterizar el Estado de Alerta en los trabajadores del Cuerpo de Bomberos, así como establecer relaciones con las enfermedades provenientes del trabajo, además de identificar estrategias de intervención sugeridas por los trabajadores para mejorar su calidad de vida. Éstos desarrollan actividades sometidos a eventos conyunturales inesperados en los que la carga física y psíquica puede predisponer al Estado de Alerta. Se caracteriza como una investigación del área humano-social, exploratoria, con abordaje cualitativo que involucró 24 trabajadores. Para la colecta de datos, se realizó entrevista semiestructurada, compuesta por cuestiones generales y específicas. En el análisis de los datos, fue esquematizado el Estado de Alerta y su relación con enfermedades identificadas por los trabajadores, señalando la necesidad de cambios que favorezcan la mejora de la calidad de vida en el trabajo.
Keywords:

Arousal. Nursing. Job satisfaction. Quality of life.
Palabras clave: Nivel de alerta. Enfermería. Satisfacción en el trabajo. Calidad de vida. 


\section{INTRODUÇÃO}

Este estudo está baseado na tese de doutoramento de Beck (1) Da banalização do sofrimento à sua ressignificação ética na organização do trabalho, na qual - Estado de Alerta (EA) observado nos trabalhadores de enfermagem emergiu como dado relevante.

0 trabalho da enfermagem em unidades críticas é marcado pela presença de situações complexas e inusitadas, que exigem alto grau de atenção e EA constante. Além disso, estes trabalhadores exercem suas atividades em ambientes estressantes, onde as situações de emergência ocorrem como eventos rotineiros que requerem dos trabalhadores, empenho e inúmeras habilidades.

Neste sentido, o EA pode ser caracterizado por níveis de atenção e concentração elevados, sendo que, mediante a ocorrência de eventos críticos, há o aparecimento de sinais e sintomas nos trabalhadores como agitação, sudorese e ansiedade, que podem aparecer e desaparecer em seguida (especialmente tendo em vista a necessidade de tomada de decisões rápidas). Já o estado de alerta permanente (EAP) se apresenta a partir da manutenção deste estado, mesmo quando o trabalhador está fora do ambiente de trabalho.

Nesta perspectiva, evidenciam-se as semelhanças existentes entre o trabalho da enfermagem e dos bombeiros, uma vez que ambos desenvolvem atividades submetidos a eventos situacionais inesperados, nos quais a carga física e psíquica exigida vai ao encontro do EA anteriormente citado. Dessa forma, levantamse questionamentos sobre 0 significado e conseqüências destas situações no trabalho e na vida pessoal destes trabalhadores.

Ambientes fechados, estado permanente de prontidão, situações inusitadas, escalas desgastantes estão entre as diversas semelhanças encontradas no cotidiano da enfermagem e dos bombeiros, e é nessa realidade que emerge este estudo, em busca de alternativas que possam minimizar estes eventos estressantes no fazer destes trabalhadores.

0 Corpo de Bombeiros tem como missão básica a preservação da vida, do meio ambiente e do patrimônio e, por ser um órgão militar, além de exercer atividades que competem à Polícia Militar, como preservação da ordem pública, atua, também, na execução de atividades de defesa civil como: prevenção e extinção de incêndios, proteção e salvamento de vidas humanas, busca e salvamento em afogamentos, inundações, desabamentos, acidentes em geral, catástrofes e calamidades públicas. A partir daí, depreende-se que são trabalhadores com muitas atividades a desempenhar e um nível de exigência alto na sua execução.
0 interesse pela questão a ser investigada surgiu devido ao contato de alguns pesquisadores deste grupo de pesquisa com policiais militares e bombeiros nos Cursos de Urgência e Emergência oferecidos pela Escola de Saúde Pública do Estado do Rio Grande do Sul, em parceria com a Universidade Federal de Santa Maria (UFSM). Nestes encontros, muitos trabalhadores identificaram o EA em seu cotidiano laboral e explicitaram a necessidade de se estudar e mapear as manifestações desse estado, bem como as conseqüências deste nas suas vidas.

Portanto, este estudo objetivou identificar a presença e caracterizar o EA nos trabalhadores do Corpo de Bombeiros; estabelecer prováveis relações entre as doenças do trabalho na Corporação e o EA; e identificar estratégias de intervenção sugeridas por estes trabalhadores no sentido de melhorar sua qualidade de vida. Desta forma, este estudo tem relevância para a saúde e para a enfermagem porque focaliza outros trabalhadores que reagem aos eventos situacionais inesperados de maneira semelhante aos trabalhadores da enfermagem.

\section{REVISÃO DE LITERATURA}

Os trabalhadores que atuam em locais como Unidades de Terapias Intensivas têm riscos que envolvem sua saúde física e mental. Esses trabalhadores muitas vezes negam ou desconhecem estes riscos, por falta de investigação que associe condições iatrogênicas do ambiente e do próprio processo de trabalho a aspectos de desconforto e malestar apresentados por eles.

Em situações em que o rearranjo da organização do trabalho não é possível, quando a relação do trabalhador com a organização é bloqueada, o sofrimento começa, pois a energia pulsional que não é descarregada no exercício do trabalho é acumulada no aparelho psíquico, ocasionando um sentimento de desprazer e tensão. A evolução deste processo, portanto, pode ocasionar distúrbios de ordem física e psíquica no trabalhador, caracterizada, muitas vezes, sob a forma de doenças psicossomáticas (2).

0 sofrimento dos trabalhadores pode ser expresso, dentre outras formas, através da insatisfação e da ansiedade. A insatisfação e a satisfação do trabalhador podem estar vinculadas a aspectos como: condições de trabalho (ambiente físico, químico e biológico, condições de higiene e segurança) e a organização do trabalho (divisão do trabalho, das tarefas, as relações de poder, as questões de responsabilidades e 0 relacionamento entre as pessoas) ${ }^{(2)}$. 
É fundamental para os trabalhadores de algumas profissões, como, por exemplo, a enfermagem e os bombeiros, estarem em EA, pois é este estado que assegura a qualidade do atendimento dispensado às pessoas, bem como bons resultados na sua atuação. Mas se, por um lado, este EA é fundamental na realização de um trabalho com qualidade, por outro, o prolongamento do mesmo poderá trazer sérios prejuízos à vida e à saúde destes trabalhadores. Como conseqüências deste EA prolongado, pode-se relacionar os transtornos de sono, o desgaste físico e mental, o cansaço do trabalhador ao sair do trabalho, o medo de adoecer em função desta sobrecarga, a irritabilidade, as brigas com a família por motivo fútil, o aparecimento de conflitos internos e externos, dentre outros aspectos (1).

$0 \mathrm{EA}$, quando permanente, sem estratégias compatíveis de enfrentamento, parece contribuir para 0 adoecimento dos trabalhadores. No entanto, a percepção e 0 enfrentamento deste estado dependem de cada indivíduo, sendo fundamental no sentido de assegurar mais ou menos qualidade na realização profissional e pessoal.

A idéia de qualidade de vida no trabalho congrega diversos aspectos relativos às condições e ambientes de trabalho em empresas tanto públicas quanto privadas, não se resumindo em análises restritivas ao capital ou trabalho, mas, ainda, aos aspectos relativos ao mundo subjetivo, ou seja, sentimentos, experiências, anseios, ideologias, valores e interesses (3: 387).

Neste sentido, a qualidade de vida do trabalhador envolve questões intrinsecamente ligadas às novas tecnologias e seu impacto para a saúde e o meio ambiente; aos salários, incentivos e participação nos lucros das empresas; à criatividade, autonomia, grau de controle e quantidade de poder dos trabalhadores sobre o processo de trabalho ${ }^{(4)}$.

0 controle que engloba a autonomia e o poder que os trabalhadores têm sobre os processos de trabalho ${ }^{(4: 154)}$ é um dos elementos mais importantes na qualidade de vida no trabalho. A noção de controle deve ser entendida como a possibilidade de os trabalhadores identificarem o que os incomoda, os fazem sofrer, adoecer, morrer e acidentar-se e articulada à viabilidade de interferir em tal realidade (4:154). Portanto, controlar a organização do trabalho requer a condição de ser sujeito na situação.

\section{METODOLOGIA}

0 presente estudo caracteriza-se como uma pesquisa da área humano-social, do tipo exploratório, com abordagem qualitativa, sendo desenvolvida no
Corpo de Bombeiros de um município do interior do Estado do Rio Grande do Sul, órgão ligado à Brigada Militar e à Secretaria de Segurança e Justiça.

0 Corpo de Bombeiros, no ano de 2005, era composto por 1 major, 2 capitães, 2 primeiros-tenentes, 7 primeiros-sargentos, 1 segundo-sargento, 33 terceiros-sargentos, 5 cabos e 66 soldados, perfazendo um total de 117 trabalhadores. Neste estudo, optouse por trabalhar com uma amostra probabilística estratificada que pode ser usada quando a população se constitui de elementos e se faz necessário estabelecer procedimentos que retirem igualmente elementos de cada grupo, de modo que todos os grupos fiquem representados $\left.{ }^{(5:}{ }^{187}\right)$.

A coleta de dados envolveu uma entrevista semiestruturada na qual foram entrevistados 24 sujeitos, considerando-se a proporcionalidade dentro das categorias e a exaustão dos dados. Foi realizado sorteio para selecionar os participantes, tendo os mesmos liberdade para se incluir ou não no referido estudo. Nas situações em que o trabalhador sorteado não pôde participar do estudo (exemplo: licença por tratamento de saúde, férias) foi realizado novo sorteio, preservando-se a proporcionalidade naquele grupo.

Com relação às atividades, os trabalhadores da corporação cumprem escalas de 12 horas diárias, com turnos das $8 \mathrm{~h}$ às $20 \mathrm{~h}$ e das $20 \mathrm{~h}$ às $8 \mathrm{~h}$, sendo que, conforme informações recebidas, todos realizam as mesmas atividades independentemente de sua graduação.

0 que torna a entrevista um instrumento privilegiado de coleta de informações é a possibilidade de a fala ser reveladora de condições estruturais, de sistemas de valores e normas e, ao mesmo tempo, ter a magia de transmitir, através de um porta-voz, as representações de grupos determinados, em condições históricas, sócioeconômicas e culturais específicas (6: 109).

Para validar o referido instrumento, realizamos cinco entrevistas com membros da população de bombeiros, com o objetivo de perceber se não havia dificuldade de entendimento nas questões propostas.

Inicialmente, o projeto tramitou pelo Comitê de Ética do Centro de Ciências da Saúde, sendo aprovada sua implementação. Em seguida, foi agendado um encontro com o major que coordena o trabalho da corporação, a quem foram apresentados os objetivos da pesquisa. Após a autorização, foram feitos contatos com os bombeiros no sentido de verificar seu desejo de inclusão no estudo, bem como as datas favoráveis para a realização das entrevistas. Antes de ser entrevistado, o informante teve acesso ao Termo de Consentimento Livre e Esclarecido conforme preconiza a Resolução 196/96.

Todas as entrevistas foram realizadas no local de trabalho, em uma sala reservada apenas com a 
presença do pesquisador e do participante, em horário previamente combinado. As entrevistas foram gravadas, com a aquiescência dos participantes, para, posteriormente, serem transcritas. Após a entrevista, sem a presença do participante, o pesquisador também registrava as suas percepções sobre o entrevistado como, por exemplo, referências às atitudes e comportamentos do entrevistado durante o encontro. Este procedimento tinha como objetivo captar informações que, no momento da análise, pudessem contribuir para o processo de compreensão da realidade em estudo.

A análise das entrevistas foi feita mediante leitura exaustiva das mesmas para apreensão inicial de seu conteúdo. Vencida a primeira etapa, foi revisada cada questão, individualmente, no sentido de estabelecer as categorias temáticas que emergiram no decorrer do estudo.

\section{APRESENTAÇÃO E DISCUSSÃO DOS RESULTADOS}

A primeira pergunta questionava se os bombeiros gostavam de trabalhar na Corporação e por quê. Evidenciou-se que $100 \%$ dos participantes gostam de trabalhar na Corporação, ou seja, 13 (54,17\%) trabalhadores justificam esta resposta pela possibilidade de poder ajudar e salvar as pessoas; $10(41,66 \%)$, pelo fato de se identificarem com a profissão e se sentirem realizados; e $1(4,17 \%)$, pela influência familiar.

0 fato de a maioria dos trabalhadores gostar de trabalhar no Corpo de Bombeiros por poder ajudar/salvar as pessoas muitas vezes pode-se vincular a um sentimento de heroísmo, de valorização da profissão, quando realizam suas atividades com êxito. Neste contexto, o trabalho não é apenas um modo de ganhar a própria vida, mas um status social ( ${ }^{(7: 27)}$, o que é identificado na fala dos trabalhadores ao dizerem que se sentem gratificados pelo reconhecimento da população.

Neste sentido, antes de sermos trabalhadores, somos pessoas que precisamos buscar a realização pessoal, o que, sem dúvida, refletirá em todas as etapas da vida, incluindo o processo de trabalho ${ }^{(8: 48)}$.

$\mathrm{Na}$ questão seguinte, foram questionados se teriam motivos para trocar de atividade de trabalho e, em caso afirmativo, quais seriam estes motivos. Desse modo, 22 trabalhadores $(91,66 \%)$ informaram não ter motivos e $2(8,34 \%)$ responderam ter motivos, sendo que, destes últimos, 1 (4,17\%) justificou-se com o fato de morar em outra cidade e ter de se deslocar para esta cidade, fato que gera diminuição do contato com a família.
É evidente que, quanto maior a jornada, menor será o tempo para o convívio familiar, e, quanto maior o cansaço, mais será afetada a qualidade do relacionamento do trabalhador com seus familiares (9:203).

0 outro bombeiro $(4,17 \%)$ referiu que se sente insatisfeito pela falta de apoio dos colegas de graduação mais elevada. Neste sentido, é necessário evidenciar que, quando a relação operário-chefia é marcada pelo autoritarismo, pode desencadear nos trabalhadores intensa mágoa por não serem reconhecidos pelos seus esforços, por considerarem que a chefia atua ferindo sua dignidade por diversos meios, por sentirem-se preteridos por vantagens atribuídas a outros companheiros ${ }^{(9: 154)}$. Outras vezes, os conflitos destas relações podem gerar tensão, injustiça, coação, medo de perder o emprego, perturbações do sono entre outros. Foi informado que todos os trabalhadores desenvolvem as mesmas atividades independentemente $d a$ hierarquia institucional, porém é importante lembrar que esta é uma instituição militar onde as normas são rígidas e devem ser cumpridas, o que retira do trabalhador a possibilidade de criar e sentir-se participante da construção do seu processo de trabalho. 0 controle engloba a autonomia e o poder que os trabalhadores têm sobre os processos de trabalho, sendo este um dos elementos mais importantes da qualidade de vida no trabalho" (4: 154).

A próxima questão procurou saber se os bombeiros apresentavam doenças diagnosticadas e se faziam acompanhamento/ tratamento das mesmas. Dessa forma, $17(70,83 \%)$ referiram não apresentar doenças diagnosticadas e 7 $(29,17 \%)$ afirmaram apresentar algum tipo de doença; destes últimos, somente $1(4,17 \%)$ trabalhador faz acompanhamento da mesma. Dentre as doenças citadas, a que apareceu em maior número foi 0 estresse, sendo referido por $4(16,66 \%)$ trabalhadores. Ainda foram referidas arritmias cardíacas e problemas oculares, $1(4,17 \%)$, sobrecarga osteomuscular, 1 , (4,17\%), e insônia, 1 (4,17\%).

Estar estressado é um estado do organismo, após o esforço de adaptação, que pode produzir deformações na capacidade de resposta, atingindo o comportamento mental e afetivo, o estado físico e o relacionamento com as pessoas ${ }^{(10: 28)}$. 0 estresse é desencadeado por estímulos que podem ser internos ou externos e pode ser observado em, pelo menos, duas dimensões, ou seja, como processo e estado. Como processo, significa tensão diante de uma situação 
de desafio, por ameaça ou conquista; como estado, significa resultado positivo ou negativo da tensão realizada pela pessoa. Estas dimensões são facilmente detectadas no Corpo de Bombeiros quando referem, por exemplo, ansiedade e alterações no sono, pois a tensão diante de uma situação de desafio é vivenciada a cada ocorrência e cada trabalhador atribui um significado a ela.

0 estresse intenso e prolongado pode aumentar, consideravelmente, o risco de doenças coronarianas, o que também foi citado pelos trabalhadores. Dentre os fatores que podem contribuir para isto destacamse a competição, grandes esforços físicos (problemas osteomusculares), as exaustivas cargas de trabalho e o próprio estado de alerta.

A insônia, que aparece com 14,28\% de freqüência entre os trabalhadores, é um dos sintomas mais comuns que uma pessoa pode apresentar quando passa por uma situação que exige dela esforço, embora este não seja o único fator etiológico desse problema ${ }^{(10: 94)}$. Segundo comentário dos autores, pesquisadores calculam que $1 / 3$ da população adulta apresenta dificuldades em relação ao sono, mas apenas $17 \%$ dessa população recorre ao tratamento médico. A insônia muitas vezes pode ser transitória, estar relacionada a um momento estressante ou a quadros de ansiedade, depressão, uso de drogas como álcool, cafeína, dentre outros (10:94).

Quando questionados se trabalhavam em EA, $22(91,66 \%)$ trabalhadores responderam afirmativamente e $2(8,34 \%)$ negaram a presença do EA. Dos que verbalizaram que trabalham em EA, 14 $(63,63 \%)$ afirmaram estar sempre em EA; 2 (9,09\%) relacionaram este estado com a responsabilidade de receber/transmitir o chamado para as equipes de ocorrências, 2 (9,09\%) relataram que o tempo de serviço proporcionou experiência profissional, tornando-os mais seguros do trabalho a ser realizado e amenizando o mesmo, e $3(13,63 \%)$ relacionaram o EA com o toque do bezorro, que é um som/alarme/ sirene acionado na corporação quando recebem algum chamado, e 1 (4,56\%) não respondeu.

Dos $2(8,34 \%)$ trabalhadores que disseram não trabalhar em EA, um evidenciou tensão no trabalho caracterizada por um nível de atenção elevada, e o outro disse ficar assustado ao escutar o bezorro, ou seja, a sirene, o que nos faz pensar que pode haver uma negação do EA.

Neste sentido, um dos sujeitos da pesquisa referiu que os bombeiros devem estar "sempre alerta 25 horas por dia...", uma vez que vivenciam, cotidianamente, resgates, buscas e salvamentos ou combate a incêndios.

$\mathrm{Na}$ pergunta seguinte, procurou-se saber se este EAP é identificado pelos trabalhadores em seu cotidiano de trabalho. Evidenciou-se que 14 $(63,63 \%)$ trabalhadores referiram identificar o EAP e $10(36,37 \%)$ informaram que não o identificam permanentemente. Assim, dos que identificam o EAP, $7(38,88 \%)$ o evidenciam na presença do toque de algum tipo de sirene que se assemelhe ao bezorro; 2 $(11,12 \%)$ informaram que o percebem ao dormir, ou seja, não conseguem dormir tranqüilamente; 1 (5,55\%) referiu que, em situações de risco, como em dias de vendavais, tempestades, enchentes, o EAP é percebido; $1(5,55 \%)$ disse que a violência da sociedade 0 deixa constantemente em EAP; 1 (5,55\%) evidenciou o EAP antes de ir trabalhar, ficando na expectativa de alguma ocorrência; 1 (5,55\%) relatou que percebe o EAP quando acredita que poderia ter desenvolvido melhor suas funções; e 1 (5,55\%) disse perceber o EAP, mas não o relaciona com nenhum evento específico.

Dos dez bombeiros que não identificam o EAP, 5 (50\%) referiram perceber-se em alerta na presença de sirenes, o que significa dizer que eles manifestam 0 EA mas não o percebem cotidianamente; $3(30 \%)$ afirmaram ser capazes de separar o serviço de sua vida social, não vivendo em EAP, e 2 (20\%), embora também tenham dito que não percebem o EAP, sentem alguma alteração física quando se dirigem a uma ocorrência ou sabem dela.

Nesta questão, constatou-se que muitos trabalhadores vivem em $E A$, mas não o percebem ou negam sua existência, pois, quando questionados, referiram que não o identificam, porém apresentam justificativas contraditórias. Um dos eventos nocivos que podem ocasionar reações nos indivíduos é a fase da negação das dificuldades que estão sendo vivenciadas, como um mecanismo de defesa que a mente usa para se proteger da extrema ansiedade (11). Estar em EA é fundamental para que a equipe de enfermagem de unidades críticas verifique alterações precoces e auxilie na recuperação dos pacientes, e, até mesmo, evite sua morte, mas é necessário ter consciência e procurar alternativas que auxiliem os trabalhadores a viverem melhor, convivendo com esta situação inevitável (1).

Esta afirmação é aplicável ao corpo de bombeiros uma vez que estes vivem em situações limítrofes que, muitas vezes, exigem o EA para evitar, prevenir desastres ou socorrer vítimas de algum acidente. 
0 EA alerta pode passar por vários níveis, relacionandose ao andamento do turno de maneira geral, podendo causar uma ansiedade significativa no trabalhador. 0 EAP, sem estratégias compatíveis de enfrentamento, parece contribuir para 0 adoecimento dos trabalhadores, sendo que a percepção e o enfrentamento do mesmo dependem de cada indivíduo, no sentido de assegurar mais ou menos qualidade de vida.

Ao serem interrogados quanto à identificação de alterações físicas ou emocionais decorrentes do EA e quais seriam estas alterações, 12 (50\%) trabalhadores disseram não identificar e 12 (50\%) afirmaram que identificam alterações de ordem física ou emocional. Destes últimos, 4 (33,33\%) disseram que apresentam taquicardia, cansaço, dores musculares ou cefaléia; 3 (25\%) identificam a presença do alcoolismo e de agitação, mas somente nos colegas; $3(25 \%)$ identificam alterações emocionais como irritação, nervosismo, tensão e estresse, e 2 (16,67\%) relataram apresentar alterações físicas e emocionais como as citadas anteriormente.

As estatísticas referentes às causas de afastamento do trabalho por doença e aposentadoria por invalidez mostram que a hipertensão arterial, doenças das articulações e transtornos mentais são as mais freqüentes, sendo estas as que causam mais afastamentos, enquanto a hipertensão é a que provoca mais aposentadorias ${ }^{(10)}$. Alguns trabalhadores, na sua fala, informaram, mesmo não sendo questionados, que realizam algum tipo de cuidado para amenizar estas alterações, e, também, foi observado que eles identificam mais alterações nos colegas do que neles mesmos. Alguns relatam que, dentro da corporação, já houve casos de suicídio de colegas decorrentes da depressão. Sabe-se que em condições de vida com estresse intenso e prolongado, luto, perdas importantes, cafeína, álcool, dentre outros, é possível desencadear manifestações depressivas importantes ${ }^{(10)}$.

$\mathrm{Na}$ seqüência da entrevista, procurou-se identificar se os trabalhadores acreditam que o EA pode contribuir para o aparecimento de doenças e de que maneira. Dessa forma, $3(12,5 \%)$ deles disseram que não acreditam e 21 (87,5\%) informaram que acreditam que 0 EA pode contribuir para 0 aparecimento de doenças. Destes últimos, 10 (47,62\%) bombeiros relacionaram o EA com problemas de saúde, como hipertensão arterial sistêmica e complicações cardiovasculares; 7 (33,34\%) com estresse, depressão e suicídio; 2 (9,52\%) disseram depender da maneira como o trabalhador enfrenta os problemas; $1(4,76 \%)$ relatou que isso ocorre a partir de problemas de saúde decorrentes das cargas físicas, e $1(4,76 \%)$ não sabia de que maneira o EA pode contribuir para 0 aparecimento de doenças.

Grande número de doenças do homem urbano contemporâneo denunciam, expressam e revelam a forma da pessoa viver, sua qualidade de vida e sua maneira de interagir com o mundo ${ }^{(10)}$.

Ainda, compondo o quadro de questionamentos desta pesquisa, foi perguntado se os bombeiros acreditam que o EA pode ser trabalhado no ambiente de trabalho ou fora dele e de que maneira. Como resultado, $19(79,16 \%)$ bombeiros relataram acreditar que o EA pode ser trabalhado; 4 $(16,67 \%)$, que não pode, e $1(4,17 \%)$ não sabia. Dos que disseram que o EA pode ser trabalhado, 5 $(26,32 \%)$ informaram que a melhor maneira de se trabalhar o EA é nos diálogos com psicólogos; 3 $(15,79 \%)$, nas conversas com profissionais da área da saúde; 3 (15,79\%), nas conversas em grupos com os demais trabalhadores; 3 (15,79\%), em palestras sobre auto-estima e relacionamento interpessoal; 3 $(15,79 \%)$, no relacionamento entre os colegas; 1 $(5,26 \%)$, na realização de exercícios físicos, e 1 $(5,26 \%)$, no contato com a natureza.

Observou-se nas entrevistas que os trabalhadores têm anseio por falar, expressar seus sentimentos, relatar o que acontece no seu dia, que diálogos, em momentos formais ou informais, poderiam contribuir para a diminuição da ansiedade vivida, e que a falta de um espaço para estes encontros é percebida por eles, assim como um relacionamento satisfatório com os colegas poderia contribuir para uma melhor qualidade de vida no trabalho.

0 questionamento que finalizou 0 instrumento de coleta de dados foi se os trabalhadores acreditam que mudanças no local de trabalho podem interferir positivamente neste $E A$ e que mudanças seriam essas. Os dados foram: 18 (75\%) bombeiros afirmaram que mudanças no local de trabalho poderiam interferir positivamente no EA; 5 $(20,83 \%)$ disseram que não interfere, e $1(4,17 \%)$ não sabia. Dentre os trabalhadores que citaram mudanças, $3(16,67 \%)$ referiram a necessidade de mudanças no relacionamento interpessoal; $3(16,67 \%)$ solicitaram a realização de palestras; $3(16,67 \%)$ consideram que mudanças na escala de serviço seriam uma contribuição; $2(11,11 \%)$ acreditam na prática de esportes; $2(11,11 \%)$, na criação de um local apropriado para distração e descanso (sala de estar, revistas, livros); 2 (11,11\%), no 
aumento do número de funcionários; 2 (11,11\%), na compra de melhores materiais e equipamentos utilizados no serviço e $1(5,55 \%)$ acredita que seria importante aumentar o trabalho educativo nas escolas como estratégia para diminuir o número de trotes telefônicos recebidos pela corporação.

Ao analisar estes resultados, pode-se considerar que se tratam de aspectos relativamente simples, que poderiam ser providenciados, e que o fato de os bombeiros identificá-los é positivo. Entretanto, os trabalhadores devem procurar criar estes espaços na tentativa de amenizar seus anseios, uma vez que eles têm responsabilidades que competem a cada um e que precisam tomar atitudes que combatam o processo de banalização do trabalho, para, desta forma, sentir prazer, conforto e bem-estar, os quais podem auxiliar na construção de um cotidiano laboral mais equilibrado ${ }^{(12) .}$

\section{CONCLUSÃO}

Este estudo possibilitou identificar e caracterizar a presença do EA nos trabalhadores do Corpo de Bombeiros, bem como buscou estabelecer prováveis relações entre as doenças provenientes do trabalho na Corporação e o EA, além de identificar estratégias de intervenção sugeridas por estes trabalhadores no sentido de melhorar sua qualidade de vida.

É fundamental para os trabalhadores de algumas profissões, como, por exemplo, a enfermagem e os bombeiros, estarem em estado de alerta, pois é este estado de prontidão que assegura a qualidade do atendimento dispensado às pessoas, assim como bons resultados da sua atuação. Esta atitude pode determinar o êxito na realização da atividade destes trabalhadores.

\section{Referências}

1. Beck CLC. Da banalização do sofrimento à sua re-significação ética na organização do trabalho. [tese de doutorado]. Florianópolis (SC): Universidade Federal de Santa Catarina/ UFSC; 2000.

2. Dejours C, Adouchelli E, Jayeit C. Psicodinâmica do trabalho: contribuições da Escola Dejouriana à análise da relação prazer, sofrimento e trabalho. São Paulo (SP): Atlas; 1994.

3. Farias SNP, Zeitoune RCG. A interferência da globalização na qualidade de vida no trabalho: a percepção dos trabalhadores de enfermagem. Esc. Anna Nery Rev Enferm, 2004 dez; 8 (3): 386-92.
Destaca-se que $91,66 \%$ dos trabalhadores pesquisados trabalham em EA, e, destes, $63,63 \%$ afirmam estar em EAP. Se, por um lado, este estado de alerta é fundamental na realização de um trabalho com qualidade, por outro, o prolongamento do mesmo poderá trazer sérios prejuízos à vida e à saúde destes trabalhadores. Como conseqüências deste estado de alerta prolongado, pode-se relacionar os transtornos de sono, o desgaste físico e mental, o cansaço do trabalhador ao sair do trabalho, o medo de adoecer em função desta sobrecarga, a irritabilidade em casa, as brigas com a família por motivo fútil, dentre outros aspectos.

Frente aos resultados obtidos, pode-se constatar que a inclusão de práticas, como o esporte, a realização de encontros educativos, a criação de local apropriado para descanso e lazer, a disponibilidade de materiais e equipamentos necessários para a realização do trabalho com menos riscos e mais qualidade podem contribuir para a melhoria da qualidade de vida no trabalho.

Diante deste contexto, torna-se necessário buscar alternativas que combatam o processo de banalização, sob pena de não alcançarem o prazer, o conforto, o bem-estar, os quais auxiliam na construção de um cotidiano laboral mais equilibrado e, assim, perderem de vista seus ideais, faróis que iluminam o caminho ${ }^{(12)}$.

A partir deste estudo, conclui-se que existem estreitas relações entre 0 trabalho desenvolvido pela enfermagem em unidades críticas e o dos bombeiros, apesar de haver algumas diferenças nos seus processos. Neste sentido, eles têm como pontos convergentes o EA e o EAP para alguns trabalhadores, além de atuarem com indivíduos e comunidades em situações de risco, nas quais a manutenção da vida depende de uma atuação competente e adequada.

4. Lacaz FAC. Qualidade de vida no trabalho e saúde/doença. Rev Ciência e Saúde Coletiva 2000: 5 (1): 151-162.

5. Leopardi MT, Beck CLC, Gonzales RMB, Nietsche, EA. Metodologia da Pesquisa em Saúde. Santa Maria (RS): Pallotti; 2002.

6. Minayo MCS. 0 desafio do conhecimento: pesquisa qualitativa em saúde. São Paulo (SP): Hucitec Abrasco; 1994.

7. Gonzales, RMB. Sofrimento na práxis de enfermagem: real ou deslocado em seu sentido? [tese de doutorado]. Florianópolis (SC): Universidade Federal de Santa Catarina/ UFSC; 2000.

8. Leopardi, MT. Qualidade de Vida no Trabalho: a busca de um trabalhador omnilateral. Trabalho apresentado no Congresso Brasileiro de Enfermagem; 1994; out/nov. Porto Alegre (RS), Brasil: ABEn; 1994. 


\section{Sobre as Autoras}

Janeiro (RJ): Cortez; 1994.

10. Limongi França AC, Rodrigues AL. Stress e trabalho: uma abordagem psicossomática. São Paulo (SP): Atlas; 2002.

11. Taylor CM. Fundamentos da Enfermagem Psiquiátrica (de Mereness). Porto Alegre (RS): Artes Médicas; 1992.

12. Carvalho 0. Aula do curso de introdução a vida intelectual. 1987. Citado em: 11 nov. 2005. Disponível em: http:// www.olavodecarvalho.org/apostilas/ideais.htm.

\section{Rosa Maria Bracini Gonzáles}

Professora Adjunto do Departamento de Enfermagem da UFSM, Doutora em Enfermagem: Área de Concentração: Filosofia da Enfermagem UFSC. Vice líder do Grupo de Pesquisas Trabalho, Saúde, Educação e Enfermagem. Coordenadora do Projeto.

\section{Carmem Lúcia Colomé Beck}

Professora Adjunto do Departamento de Enfermagem da UFSM, Doutora em Enfermagem: área de concentração: Filosofia da Enfermagem UFSC. Líder do Grupo de Pesquisas Trabalho, Saúde, Educação e Enfermagem UFSM.

\section{Joanita Cechin Donaduzzi}

Acadêmica do $7^{\circ}$ semestre do Curso de Enfermagem da UFSM. Membro do Grupo de Pesquisas Trabalho, Saúde, Educação e Enfermagem UFSM. Bolsista de Iniciação Científica - FAPERGS.

\section{Lílian Medianeira Coelho Stekel}

Acadêmica do $7^{\circ}$ semestre do Curso de Enfermagem da UFSM. Membro do Grupo de Pesquisas Trabalho, Saúde, Educação e Enfermagem UFSM. Bolsista de Iniciação Científica - PIBIC. 